\title{
The burden of medication overuse headache and patterns of switching and discontinuation among triptan users: a systematic literature review
}

\author{
Alison M. Deighton ${ }^{1 *}$, Linda A. Harris², Karissa Johnston ${ }^{1}$, Shomari Hogan², Lynn A. Quaranta², \\ Gilbert L'Italien ${ }^{2}$ and Vlad Coric ${ }^{2}$
}

\begin{abstract}
Background: A synthesis of real-world discontinuation and switching patterns among triptan users and rates of acute medication use among patients with medication overuse headache $(\mathrm{MOH})$ is needed to better understand the burden among patients with migraine. The study objectives were to: (1) synthesize rates of switching and discontinuation from triptans; (2) characterize acute medication use among patients with $\mathrm{MOH}$; and (3) describe the associated burden.
\end{abstract}

Methods: A systematic literature review was conducted, under the Preferred Reporting Items for Systematic Review guidelines, using MEDLINE/EMBASE from database inception to July 2019. The search strategy targeted studies of adults with migraine, and included terms related to migraine and its treatment. Continuous variables were summarized using means, standard deviations, and ranges. Dichotomous and categorical variables were summarized using the number and proportion of individuals.

Results: Twenty studies were included; seven describing patterns of switching and discontinuation among triptan users, and 13 characterizing triptan overuse among patients with $\mathrm{MOH}$. High rates of switching to non-specific acute medications and low two-year retention rates were reported; among US samples switching to opioids at the first refill (18.2\%) or after 1-year (15.5\%) was frequent. Compared to persistent use of triptans, switchers experienced greater headache related impact and either no improvement or increased headache-related disability. Rates of medication overuse by agent among patients with $\mathrm{MOH}$ varied greatly across the included studies, and only one study described factors associated with the risk of $\mathrm{MOH}$ (e.g. duration of medication overuse). Medication agent, increased headache frequency $(p=.008)$, and increased disability $(p=.045)$ were associated with unsuccessful withdrawal; patients overusing triptans were more successful at withdrawal than those overusing opioids or combination analgesics $(P<.0001)$.

Conclusions: The evidence summarized here highlights that rates of WCS are low and many patients turn to other acute medication at their first refill. Patients may experience no improvement in disability when switching from one triptan agent to another, or experience increasing disability and/or increasing migraine frequency when turning to traditional acute treatment for migraine. Variability in health care settings, patient severity, and study design contributed to heterogeneity across the synthesis.

\footnotetext{
*Correspondence: adeighton@broadstreetheor.com

${ }^{1}$ Broadstreet HEOR, 201-343 Railway St, Vancouver, BC V6A 1A4, Canada

Full list of author information is available at the end of the article
}

(C) The Author(s) 2021. Open Access This article is licensed under a Creative Commons Attribution 4.0 International License, which permits use, sharing, adaptation, distribution and reproduction in any medium or format, as long as you give appropriate credit to the original author(s) and the source, provide a link to the Creative Commons licence, and indicate if changes were made. The images or other third party material in this article are included in the article's Creative Commons licence, unless indicated otherwise in a credit line to the material. If material is not included in the article's Creative Commons licence and your intended use is not permitted by statutory regulation or exceeds the permitted use, you will need to obtain permission directly from the copyright holder. To view a copy of this licence, visit http://creativecommons.org/licenses/by/4.0/. The Creative Commons Public Domain Dedication waiver (http://creativeco mmons.org/publicdomain/zero/1.0/) applies to the data made available in this article, unless otherwise stated in a credit line to the data. 
Keywords: Migraine, Triptans, Switching, Discontinuation, Medication overuse headache, Burden

\section{Introduction}

Migraine is the most debilitating of all health conditions among those younger than 50 years [1]. As the prevalence of migraine is greatest among patients aged 35-49years of age (i.e. working age) [2, 3], the reduced ability to function during untreated migraine attacks has significant financial impacts at the societal level [4], in the form of absenteeism and presenteeism [5, 6]. Available options for the acute treatment of mild-to-moderate headache include simple analgesics (e.g., aspirin, acetaminophen), nonsteroidal anti-inflammatory drugs (NSAIDS; e.g., ibuprofen, naproxen), opioid analgesics, butalbital-containing analgesic products, and over-the-counter analgesics in combination with caffeine [7, 8]. Following diagnosis, migraine-specific agents may be prescribed for acute treatment, including Serotonin 5-HT1B/1D receptor agonists (triptans,) and Ergot derivatives [7, 9, 10]. Triptans have been considered standard of care $[\mathrm{SoC}]$ for the acute treatment of moderate-to-severe migraine for more than 20 years [11].

Approximately 53\% of triptan users report at least one unmet need [12], including efficacy and tolerability challenges or adverse events, and $18 \%$ of all patients with migraine are contraindicated to triptans due to cardiovascular conditions [11]. Compared to patients who respond to treatment with triptans, patients who do not respond have significantly increased headache frequency, greater impact on health-related quality of life (HRQoL), increased migraine-related disability, and higher direct and indirect medical costs $[13,14]$. When an initially prescribed triptan becomes ineffective, it is recommended that a patient try another agent or switch to a combination triptan/analgesic, such as sumatriptan/naproxen, for future attacks [9]. This process of trying another triptan is called withinclass switching (WCS), while the process of adding on or switching to a new class of migraine medication is called between-class switching (BCS). A more problematic form of BCS may occur when patients switch to opioids or barbiturates. Although their use may be needed to abort severe attacks, they should generally be avoided as they may reduce patients tolerability to $\mathrm{SoC}$ therapies and increase the risk of migraine chronification $[9,10]$.

Patients with migraine who overuse acute medication are at increased risk for developing chronic migraine as well as medication overuse headache $(\mathrm{MOH})$, a highly disabling secondary headache condition with complex treatment [15-17]. To reduce the risk of $\mathrm{MOH}$, guidelines state that medication use should be limited to 10 days per month for triptans, ergot alkaloids, combination analgesics, or opioids, and 15 days per month for simple analgesics or combination acute medications $[15,18]$. Given that many patients experience more frequent migraine, than 10 days per month, there is a need for migraine-specific medication that does not carry a risk of $\mathrm{MOH}$. Currently, the pathophysiology of MOH is not entirely known; however, recent studies have found an increased risk of $\mathrm{MOH}$ associated with certain classes of acute medication such as triptans $[19,20]$. The treatment of $\mathrm{MOH}$ is complex; educating patients about their $\mathrm{MOH}$ followed by treatment with preventive medication and withdrawal (i.e. discontinuation of the overused medication) is recommended [21, 22].

Three oral medications for the acute treatment of migraine have recently been approved by the United States Food and Drug Administration: lasmiditan, a 5-hydroxytryptamine -1F (5-HT1F) receptor agonist, and two CGRP receptor antagonists, rimegepant ODT and ubrogepant [9]. The American Headache Society (AHS) recommends that these novel acute medications be considered in patients who have contraindications to the use of triptans or who have failed to respond to, or tolerate, at least two oral triptans $[8,23]$. All of the novel medications will fill the need for patients who are contraindicated to the use of triptans; however, only the two CGRP receptor antagonists will not carry a risk of $\mathrm{MOH}[6,24,25]$ as the prescribing information for lasmiditan contains a warning regarding $\mathrm{MOH}$ [24, 26-28].

While reasons for intolerability and persistence rates among triptan users have been described [29, 30], to the best of our knowledge a synthesis on the evidence of the burden of $\mathrm{MOH}$ is lacking [17, 31, 32]. A synthesis of real-world discontinuation and switching patterns among triptan users is needed to better understand the burden experienced by triptan non-responders with increased risk of developing $\mathrm{MOH}$, who must experience treatment failure across multiple cycles of migraine medications before being eligible for novel therapies under the current AHS guidelines. The objectives of this systematic review (SLR) were to: (1) synthesize real-world estimates of the number of triptan users, globally, who switch between various triptans or discontinue triptans for other therapies; (2) characterize acute medication use among patients with $\mathrm{MOH}$; and (3) describe the associated burden. 


\section{Methods}

A SLR was conducted, using MEDLINE and EMBASE databases from database inception to July 2019, to identify articles that characterize (1) patterns of switching and discontinuation among triptan users, (2) triptan overuse among patients with $\mathrm{MOH}$, and (3) describe the associated burden. The research questions described here (Fig. 1) were a subset of a broader SLR of migraine studies, and tables of the search terms and Population, Intervention, Comparators, Outcomes, Study Design (PICOS) criteria for the full SLR can be found in Suppl Tables 1 and 2.

The search strategy targeted studies of adults with migraine and included terms related to migraine and its treatment, as well as study design filters. Animal studies were excluded, and articles were limited to those published in English. Study screening and data extraction were performed in duplicate according to PRISMA guidelines [33]. Abstracts retrieved from the search strategy were independently screened by two reviewers, as were full-text articles identified for inclusion following abstract screening. Consensus was reached through discussion with a third party - under the guidance of the PICOS criteria - when reviewers initially disagreed on whether a record should be included.

Data were extracted by two reviewers; for continuous variables, the mean, median, standard deviation, and range were extracted whenever available. For dichotomous and categorical variables, the number of individuals and proportion were extracted. Study quality assessment was performed using the STROBE (Strengthening the Reporting of Observational Studies) criteria (Suppl Table 3) [34].

\section{Study and patient characteristics}

Study characteristics extracted include the study author, year of publication, sampling frame, sample size, case ascertainment, and country. Patient characteristics for studies reporting on treatment patterns among triptan users included an indicator of incident vs. prevalent triptan users, and age and sex distribution within each study. For studies reporting on triptan overuse among patients with $\mathrm{MOH}$, patient characteristics included the care setting and the treatment for $\mathrm{MOH}$, age and sex distribution, percentage of the sample with $\mathrm{MOH}$ who had a history of migraine, and headache or migraine frequency (where available).

\section{Treatment patterns}

Patterns of switching and discontinuation among triptan users were described (Fig. 2). Rates of discontinuation were characterized by the percentage of patients that discontinued triptans where no fill for a different prescription triptan agent or class of migraine-specific or non-specific prescription therapies were observed (i.e. discontinuation). Two different forms of switching patterns were summarized: 1) switching to a different triptan agent regardless of the route of administration or dose (i.e. within-class switching, WCS), and 2) switching to a different class of migraine-specific or non-specific prescription therapies (e.g. opioid, NSAID; i.e. between-class switching, BCS). Both BCS overall and by acute medication agent were extracted to inform the frequency of BCS among triptan users and the distribution of subsequent therapies. The percentage of patients with BCS across the identified studies was plotted by acute medication agent on a bar plot.

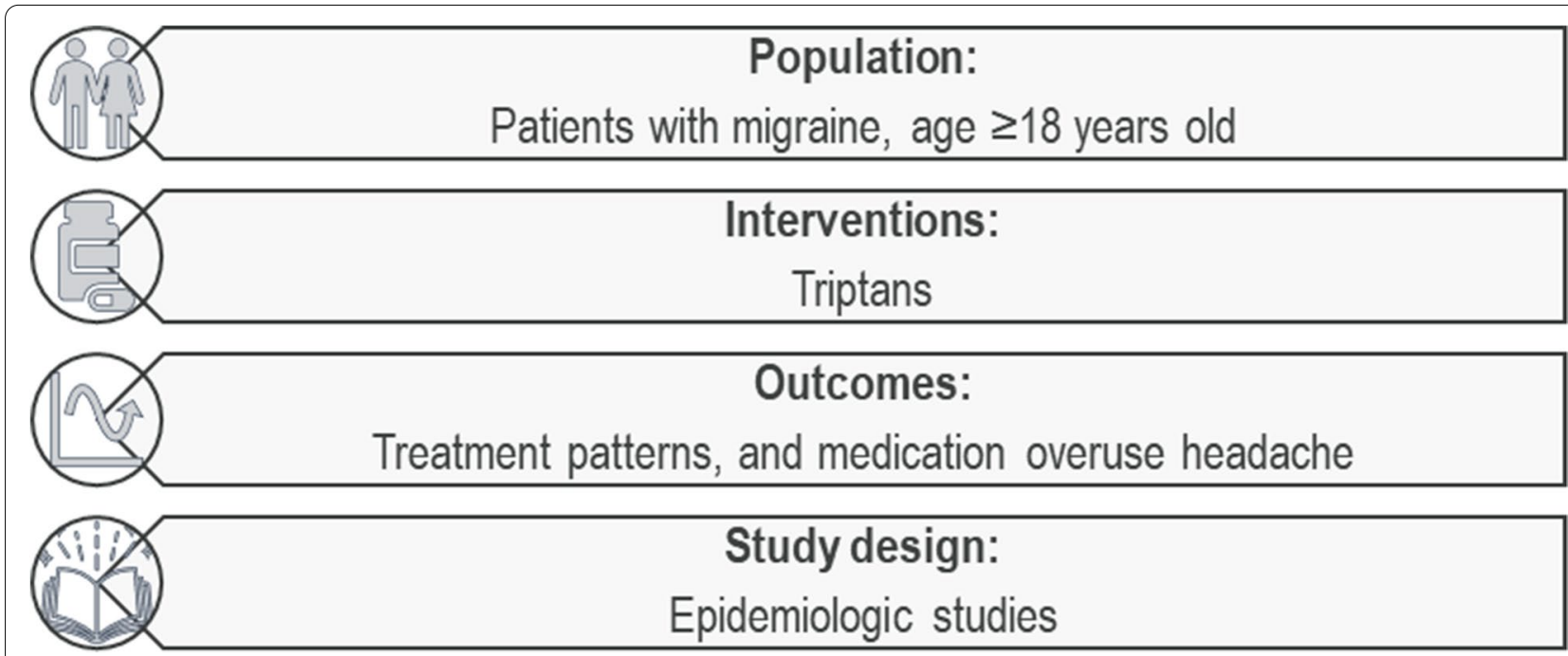

Fig. 1 PICOS criteria 


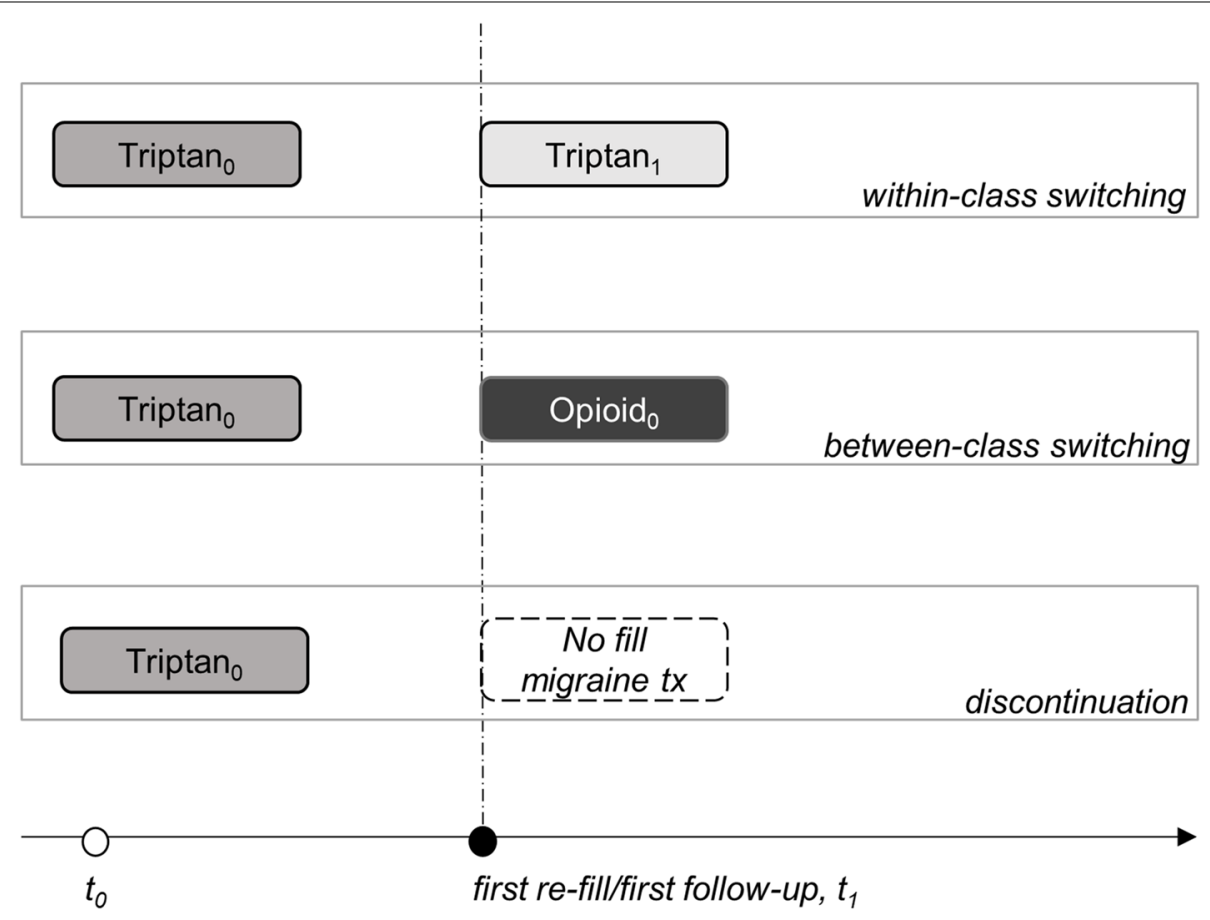

Fig. 2 Discontinuation, within class switching, and between class switching

To further characterize triptan response rates, the percentage of the sample who refilled one or more prescriptions of their index triptan within 90 days before the end of the 1 or 2-year follow-up period (i.e. one or two-year retention rate) were extracted. Impacts on HRQoL associated with discontinuation, WCS, and $\mathrm{BCS}$, as well as reasons for switching and discontinuing triptans were extracted where available, to characterize the unmet need among triptan users (both prevalent and incident users).

\section{Medication overuse headache}

Acute medication use among patients with $\mathrm{MOH}$ was characterized by the percentage of patients with $\mathrm{MOH}$ that overused triptans, simple analgesics, combination analgesics, NSAIDS, ergots, or opioids; alone or in combination. The duration and frequency of medication overuse before $\mathrm{MOH}$ developed were also extracted. Rates of unsuccessful withdrawal (inability to discontinue the overused acute medication) after one-year were summarized, and reasons for unsuccessful withdrawal were extracted where available.

\section{Results}

From 5769 records identified, 743 full-text articles were screened, and 20 studies were identified that met the PICOS criteria in the current study (Fig. 1). The 20 studies included seven treatment patterns studies among triptans users [35-41] and 13 studies among patients with MOH (Fig. 3) [42-54]. Findings from the study quality assessment (based on STROBE guidelines) are shown in Suppl Table 4. Overall the quality of the included studies was fair as the articles included failed to comply with six to 20 of the 34 STROBE items. In general, the articles provided sufficient details when reporting the setting, sample size, and variables including potential confounders, as well as they thoroughly addressed key findings with reference to the study objective. However, sources of funding, explanations for how quantitative variables were handled in the analyses, methods for missing data, and efforts to assess bias were often sparsely described, if at all reported.

\section{Study and patient characteristics}

Patient and study characteristics of the seven studies that reported on treatment patterns among triptan users are listed in Table 1 [35-41]. The identified studies included patients from North America [35, 38, 39, 41], Asia [36], and Europe [37, 40], and comprised four database studies [36, 38-40], one chart review [37], and two survey questionnaires $[35,41]$. Patients were identified in database studies through International Classification of Diseases, 10th addition (ICD-10) codes for migraine (G43) or through medical records using ICHD criteria. Two surveys assessed triptan treatment patterns among prevalent 


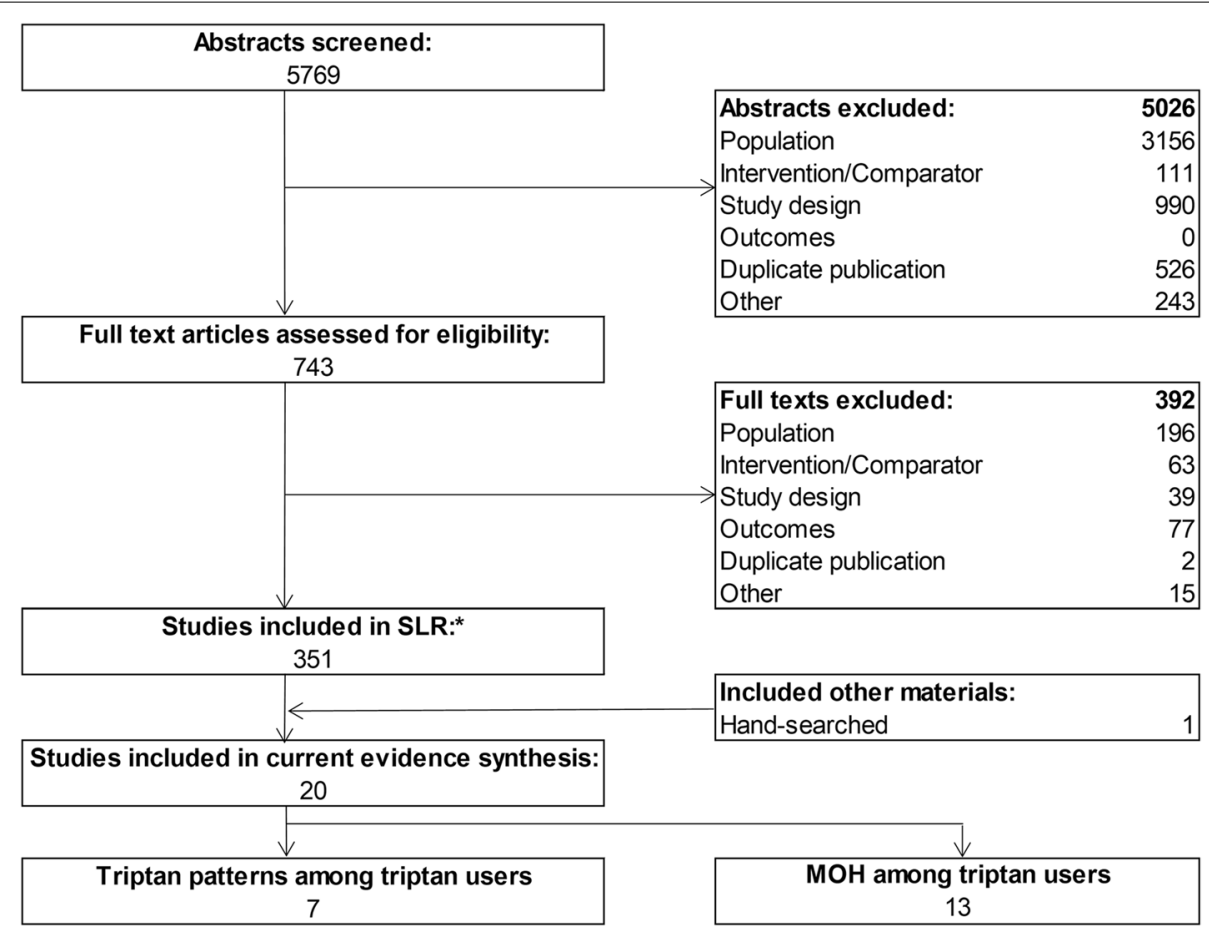

Fig. 3 PRISMA flow diagram. Abbreviations: $\mathrm{MOH}=$ Medication overuse headache; $\mathrm{SLR}=$ systematic literature review. Note: *Methods to identify studies in the current study encompassed a broader focus (see Suppl tables 1 and 2)

Table 1 Study and patient characteristics - switching and discontinuation patterns among triptan users

\begin{tabular}{|c|c|c|c|c|c|c|c|c|}
\hline Citation & $\begin{array}{l}\text { Country (Study } \\
\text { period) }\end{array}$ & Study type & $\begin{array}{l}\text { Study name/ } \\
\text { database }\end{array}$ & Sample & Subgroup & $\mathrm{n}$ & Mean age, yrs & $\%$ female \\
\hline Alam, 2018 [35] & US (2016) & $\begin{array}{l}\text { Multicenter } \\
\text { cross-sectional, } \\
\text { Survey }\end{array}$ & MAST study & Current users & Overall & 15,133 & 43.1 & 73.0 \\
\hline Chen, 2014 [36] & $\begin{array}{l}\text { Taiwan (2005- } \\
\text { 2008) }\end{array}$ & Database study & NHIR Database & Incident users & Overall & 13,951 & 41.3 & 77.0 \\
\hline Fischer, 2016 [37] & $\begin{array}{l}\text { Austria (2009- } \\
\text { 2012) }\end{array}$ & $\begin{array}{l}\text { Single center } \\
\text { chart review }\end{array}$ & $\begin{array}{l}\text { Outpatient clinic, } \\
\text { U of Innsbruck }\end{array}$ & $\begin{array}{l}\text { Incident users } \\
\text { (first/new } \\
\text { agent) }\end{array}$ & Overall & 126 & 37.2 & 88.1 \\
\hline Katic, 2011 [38] & US (2001-2005) & Database study & $\begin{array}{l}\text { i3 InVision Data } \\
\text { Mart }\end{array}$ & Incident users & Overall & 40,892 & 37.8 & 78.9 \\
\hline $\begin{array}{l}\text { Lombard, } 2018 \\
\text { [39] }\end{array}$ & US (2012-2014) & Database study & $\begin{array}{l}\text { Truven MarketS- } \\
\text { can }\end{array}$ & Incident users & Overall & 124,556 & $30.0-49.0$ & 81.0 \\
\hline \multirow{3}{*}{$\begin{array}{l}\text { Ng-Mak, } 2012 \\
{[40]}\end{array}$} & \multirow[t]{3}{*}{ EU (2006-2008) } & \multirow[t]{3}{*}{ Database study } & \multirow{3}{*}{$\begin{array}{l}\text { IMS Disease } \\
\text { Analyzer }\end{array}$} & \multirow[t]{3}{*}{ Incident users } & UK & 3618 & 41.3 & 75.6 \\
\hline & & & & & France & 2051 & 38.9 & 75.8 \\
\hline & & & & & Germany & 954 & 41.6 & 78.0 \\
\hline \multirow[t]{3}{*}{$\begin{array}{l}\text { Serrano, } 2013 \\
{[41]}\end{array}$} & \multirow[t]{3}{*}{ US (2005-2009) } & \multirow[t]{3}{*}{$\begin{array}{l}\text { Multicenter pro- } \\
\text { spective, Survey }\end{array}$} & \multirow[t]{3}{*}{ AMPP study } & \multirow[t]{3}{*}{ Current users } & $\begin{array}{l}\text { Consistency } \\
\text { group A }\end{array}$ & 700 & 47.3 & 89.0 \\
\hline & & & & & $\begin{array}{l}\text { Consistency } \\
\text { group B }\end{array}$ & 697 & 47.2 & 88.5 \\
\hline & & & & & $\begin{array}{l}\text { Consistency } \\
\text { group C }\end{array}$ & 687 & 47.1 & 88.6 \\
\hline
\end{tabular}

Consistency group A: Did not switch to another triptan in any couplet and consistently used the same triptan across years in their first eligible couplet; Consistency group B: Did not switch to an opioid/ barbiturate in any couplet and consistently used the same triptan across years in their first eligible couplet; Consistency group C: Did not switch to an NSAID in any couplet and consistently used the same triptan across years in their first eligible couplet

Abbreviations: AMPP American Migraine Prevalence and Prevention, EU Europe, IMS Information Management System, MAST Migraine in America Symptoms and Treatment, NHIR National Health Insurance Research, SC Subcutaneous inj., U University, US United States, Yrs Years 
or "current" triptan users (i.e. those who received triptans before the index date in the study) [35, 41], while the remaining studies included incident or "new" triptan users (i.e. those who did not receive triptans before the index date in the study) [36-40]. The mean age of the patients ranged from 37 to 47 years $[37,41]$, and the percentage of the sample that was female ranged from 73 to $89 \%[35,41]$.

In Table 2, the patient and study characteristics for the 13 studies which described acute medication use among patients with $\mathrm{MOH}$ are summarized [42-54]. Among the included studies, four were chart review studies $[45,47,49,50]$, four were prospective cohort studies $[48,51,53,54]$, and five were questionnaire/surveys [42-44, 46, 52]. Most studies included patients from Europe [42, 44-46, 48, 49, 51-55], while the remaining studies included patients from North America [50], Asia [47], and South America [43]. Patients were identified through medical records using ICHD criteria. All patients were seen at either inpatient or outpatient centers, and most were treated via withdrawal of the acute medication [42, 45-49, 51-53], followed by a combination of withdrawal of the offending acute medication and initiation of migraine prophylactic therapy $[44,50]$, and lastly initiation of prophylaxis alone [54]. The percentage of patients with $\mathrm{MOH}$ who had a history of migraine ranged from 8 to $100 \%$ [43, 45, 46, 52]. The mean age of patients studied with $\mathrm{MOH}$ ranged from 38 to 50 years [44, 46, 53]; de Rijk et al. included patients with $\mathrm{MOH}$ who were older than 62 years, and their mean age was 70 years [45], Among patients with $\mathrm{MOH}$, the percentage of the sample who were female ranged from 30 to $91 \%[46,49]$, and headache frequency ranged from 17 to 27 days per month $[52,53]$.

\section{Treatment patterns}

The triptan agents and route of administration used (due to differences in health care systems and study period), as well as the timepoint at which the outcomes were assessed (due to differences in study design), varied across studies reporting on rates of triptan switching and discontinuation (Table 3) [36-40]. Rates of discontinuation ranged from $11 \%$ at first follow-up visit among an Austrian sample [37] to 55\% at first refill among French and German samples (Table 3 and Fig. 4) [40]. Rates of WCS ranged from $<1 \%$ at first refill among a Taiwanese sample [36] to $15 \%$ at first follow-up visit among an Austrian sample [37]. Rates of BCS ranged from $2 \%$ at first refill among British and German samples [40] to $41 \%$ at first refill among a Taiwanese sample (Table 3 and Fig. 4) [36]. Among the overall cohort, the percentage with BCS to an opioid ranged from 0\% (at first refill; France and Germany) [40] to $18.2 \%$ (at first refill; US) [38] and to a barbiturate ranged from 0\% (at first refill; UK, France, Germany [40]; Taiwan) [36] to $2.6 \%$ (at first refill; US) (Table 3 and Fig. 4) [38]. The rate of one-year triptan retention was reported in one study among a US sample at $15 \%$ [39] and two-year retention rates ranged from $4 \%$ (Taiwan) [36] to 13\% (UK) (Table 3 and Fig. 4) [40].

Two studies described the burden associated with switching and discontinuation of triptans over time [37, 41]. Among current triptan users, change in 3-month headache-related disability was assessed from the first to second year of follow-up [41]. Compared to those who retained the same triptan agent at follow-up, neither WCS nor BCS were associated with significant improvements in headache-related disability across headache frequency strata, and among patients with more frequent migraines (10 or more headache days per month) BCS to NSAIDS was associated with significant increases in headache-related disability [41]. To the best of our knowledge, the study authors did not report the number of times patients were switched to different triptans [41]. Similarly, in Fischer et al., among patients who were treated with a new triptan agent or their first triptan, significantly higher headache-related impact scores were observed in those who had not refilled their initially prescribed triptan compared to those who had retained the same triptan at the first follow-up visit $(P<.029)$ [37]. In three of the included studies, reasons for WCS, BCS, and discontinuation were described [35-37]. Commonly reported reasons for WCS were insufficient treatment response or adverse events, reasons for BCS included contraindications for triptan use, and reasons for discontinuation from therapy included attack-freedom [35-37].

\section{Medication overuse headache}

Rates of acute medication use among patients with $\mathrm{MOH}$ are shown in Table 4 . The percentage overusing triptans varied from $2 \%$ among a Japanese sample [47] to $46 \%$ among a French sample [52]. The percentage overusing opioids ranged from $0 \%$ among Japanese [47] and German samples [49] to $48 \%$ among a North American sample [50]. The percentage overusing ergots varied from 2\% among Japanese [47] and German samples [49] to $43 \%$ among a Serbian sample [54] (Table 4). Among the sample from North America, who attended an inpatient program, opioids (48\%) and triptans (16\%) were the most commonly overused medications [50]. Creac'h et al. (France, cross-sectional survey, 2004 to 2006), included patients with $\mathrm{MOH}$ who were all triptan overusers; approximately half of the patients with $\mathrm{MOH}$ only overused triptans and the other half overused triptans in combination with another agent (e.g. triptans + combination analgesics [36\%], triptans + opioids [60\%], triptans + ergots [0.6\%]) [44]. 
Table 2 Study and patient characteristics - medication overuse headache among triptan users

\begin{tabular}{|c|c|c|c|c|c|c|c|c|c|}
\hline Citation & $\begin{array}{l}\text { Country (Study } \\
\text { period) }\end{array}$ & Study type & $\begin{array}{l}\text { Sample }(\mathrm{MOH} \\
\text { care setting, } \\
\text { treatment) }\end{array}$ & $\mathrm{n}, \mathrm{MOH}$ & $\begin{array}{l}\text { \% previous } \\
\text { history } \\
\text { migraine }\end{array}$ & $\begin{array}{l}\text { Headache } \\
\text { criteria }\end{array}$ & MHD & Mean age, yrs & $\%$ female \\
\hline $\begin{array}{l}\text { Benz et al., } 2017 \\
\text { [42] }\end{array}$ & $\begin{array}{l}\text { Switzerland } \\
(2012,2014)\end{array}$ & $\begin{array}{l}\text { Single center } \\
\text { cross-sectional, } \\
\text { survey }\end{array}$ & $\begin{array}{l}\text { Inpatient and } \\
\text { outpatient, with- } \\
\text { drawal of acute } \\
\text { medication, } \\
\text { prophylaxis }\end{array}$ & 51 & 90.0 & ICHD-II beta & NR & 47.3 & 72.5 \\
\hline $\begin{array}{l}\text { Chagas, } 2015 \\
{[43]}\end{array}$ & $\begin{array}{l}\text { Brazil (2009, } \\
2010)\end{array}$ & $\begin{array}{l}\text { Single center } \\
\text { prospective, } \\
\text { survey }\end{array}$ & Outpatient, NR & 29 & 100 & $\mid C H D-\|$ & NR & 44.2 & 82.8 \\
\hline $\begin{array}{l}\text { Creac'h et al., } \\
2009 \text { [44] }\end{array}$ & $\begin{array}{l}\text { France (2004, } \\
\text { 2006) }\end{array}$ & $\begin{array}{l}\text { Multicenter } \\
\text { cross-sectional, } \\
\text { survey }\end{array}$ & $\begin{array}{l}\text { Inpatient, } \\
\text { withdrawal of } \\
\text { acute medica- } \\
\text { tion, prophylaxis; } \\
\text { all overused } \\
\text { triptans }\end{array}$ & 163 & 99.0 & ICHD-II & 26.0 & 50.0 & 85.0 \\
\hline $\begin{array}{l}\text { de Rijk et al., } \\
2018 \text { [45] }\end{array}$ & $\begin{array}{l}\text { France (2006, } \\
\text { 2015) }\end{array}$ & $\begin{array}{l}\text { Single center, } \\
\text { chart review }\end{array}$ & $\begin{array}{l}\text { Inpatient, with- } \\
\text { drawal of acute } \\
\text { medication; } \\
\text { > } 65 \text { years }\end{array}$ & 79 & 100 & ICHD-II beta & NR & 69.5 & 79.1 \\
\hline $\begin{array}{l}\text { Grande et al., } \\
2011 \text { [46] }\end{array}$ & $\begin{array}{l}\text { Norway (2005, } \\
\text { 2008) }\end{array}$ & $\begin{array}{l}\text { Single center } \\
\text { prospective, } \\
\text { survey }\end{array}$ & $\begin{array}{l}\text { Inpatient, educa- } \\
\text { tion about medi- } \\
\text { cation overuse, } \\
\text { prophylaxis }\end{array}$ & 109 & 8.0 & ICHD-II & 22.0 & 37.5 & 30.3 \\
\hline $\begin{array}{l}\text { Imai et al., } 2007 \\
\text { [47] }\end{array}$ & Japan (NR) & $\begin{array}{l}\text { Single center } \\
\text { chart review }\end{array}$ & $\begin{array}{l}\text { Inpatient and } \\
\text { outpatient, with- } \\
\text { drawal of acute } \\
\text { medication }\end{array}$ & 47 & 90.0 & ICHD-II & NR & NR & NR \\
\hline $\begin{array}{l}\text { Katsarava et al., } \\
2003^{\mathrm{a}}[48]\end{array}$ & Germany (NR) & $\begin{array}{l}\text { Single center } \\
\text { prospective } \\
\text { cohort }\end{array}$ & $\begin{array}{l}\text { Outpatient, } \\
\text { withdrawal of } \\
\text { acute medica- } \\
\text { tion }\end{array}$ & 96 & 71.0 & ICHD-I & NR & 43.0 & 81.0 \\
\hline $\begin{array}{l}\text { Kluonaitis et al., } \\
2017 \text { [49] }\end{array}$ & $\begin{array}{l}\text { Lithuania (2015, } \\
\text { 2016) }\end{array}$ & $\begin{array}{l}\text { Single center } \\
\text { chart review }\end{array}$ & $\begin{array}{l}\text { Outpatient, likely } \\
\text { withdrawal of } \\
\text { acute medica- } \\
\text { tion, patients } \\
\text { on prophylactic } \\
\text { medication were } \\
\text { excluded }\end{array}$ & 87 & 67.0 & ICHD-II beta & 24.1 & 43.8 & 90.8 \\
\hline $\begin{array}{l}\text { Lake et al., } 2009 \\
\text { [50] }\end{array}$ & $\begin{array}{l}\text { US and Canada } \\
\text { (NR) }\end{array}$ & $\begin{array}{l}\text { Single center } \\
\text { chart review }\end{array}$ & $\begin{array}{l}\text { Inpatient, } \\
\text { withdrawal from } \\
\text { acute mediation, } \\
\text { prophylaxis, cog- } \\
\text { nitive-behavioral } \\
\text { therapy }\end{array}$ & 158 & 85.0 & ICHD-II & NR & 40.0 & 79.4 \\
\hline $\begin{array}{l}\text { Limmroth et al., } \\
2002^{a}[51]\end{array}$ & Germany (NR) & $\begin{array}{l}\text { Single center } \\
\text { prospective } \\
\text { cohort }\end{array}$ & $\begin{array}{l}\text { Outpatient, } \\
\text { withdrawal of } \\
\text { acute medica- } \\
\text { tion }\end{array}$ & 96 & 71.0 & ICHD-I & NR & 43.0 & 81.0 \\
\hline $\begin{array}{l}\text { Radat et al., } 2005 \\
\text { [52] }\end{array}$ & France (NR) & $\begin{array}{l}\text { Single center } \\
\text { cross-sectional, } \\
\text { survey }\end{array}$ & $\begin{array}{l}\text { Inpatient, with- } \\
\text { drawal of acute } \\
\text { medication }\end{array}$ & 41 & 100 & ICHD-II & 27.0 & NR & NR \\
\hline $\begin{array}{l}\text { Zeeberg et al., } \\
2006 \text { [53] }\end{array}$ & $\begin{array}{l}\text { Denmark (2002, } \\
\text { 2003) }\end{array}$ & $\begin{array}{l}\text { Single center } \\
\text { prospective } \\
\text { cohort }\end{array}$ & $\begin{array}{l}\text { Outpatient, } \\
\text { withdrawal of } \\
\text { acute medica- } \\
\text { tion }\end{array}$ & 216 & 53.0 & ICHD-II & 17.0 & 48.0 & 73.0 \\
\hline $\begin{array}{l}\text { Zidverc-Trajkovic } \\
\text { et al, } 2007 \text { [54] }\end{array}$ & $\begin{array}{l}\text { Serbia (2000, } \\
\text { 2005) }\end{array}$ & $\begin{array}{l}\text { Single center } \\
\text { prospective } \\
\text { cohort }\end{array}$ & $\begin{array}{l}\text { Inpatient, } \\
\text { prophylaxis }\end{array}$ & 240 & 67.1 & ICHD-II & 24.0 & 41.5 & 75.8 \\
\hline
\end{tabular}

Abbreviations: ICHDThe International Classification of Headache Disorders, MOH Medication overuse headache, MHD Monthly headache days, NR Not reported, US United States, Yrs Years

a Same patient population, different outcomes 
One study, a prospective study of patient with $\mathrm{MOH}$ in Germany, reported on the duration and frequency of medication use prior to the diagnosis of $\mathrm{MOH}$ [51]. Limmroth et al. found that overuse of triptans lead to more rapid onset of $\mathrm{MOH}$ (1.7 years) than ergots (2.7 years) and analgesics (4.8years; including combination, simple, and opioids analgesics) [51]. Compared to analgesics use as a whole, overuse of opioids led to more rapid onset of $\mathrm{MOH}$ (2.2 years).

After one-year, the percentage of patients with $\mathrm{MOH}$ who were unsuccessful in withdrawing from their overused medication ranged from 3\% (Serbia, prospective cohort study, inpatient setting with prophylaxis, 2000 to 2005) [54] to $19 \%$ (Germany, prospective cohort study, outpatient withdrawal of acute medication, study period NR) [48]. Medication agent $[48,53]$, increased headache frequency $(p=.008)$ [54], and increased disability $(p=.045)$ [54] were associated with unsuccessful withdrawal; patients overusing triptans were more successful at withdrawal than those overusing analgesics overall $(P<.0001-\leq .002)$, and specifically opioids, or combination analgesics $(P<.0001)[48,53]$.

\section{Discussion}

In the identified studies describing treatment patterns, rates of WCS were low, and many new triptan users switched from their index triptan to another class of medication at their first refill; most notably high rates of BCS to opioids were observed among US populations compared to non-US/other populations [38, 39]. Among the US samples identified in this review, 18.2\% at first refill or $15.5 \%$ after the first year switched from their index triptan to an opioid [38, 39]. Compared to consistent treatment with the same triptan after 1 year, WCS was not associated with improvement in headacherelated disability and BCS to certain acute medication classes was associated with increases in headache-related disability [41]. High rates of switching to non-specific acute medications and low two-year retention rates demonstrate a lack of tolerable triptan options. Among patients with $\mathrm{MOH}$ treated at inpatient and outpatient clinics, withdrawal was more difficult among patients with increased headache frequency, increased disability, or among those over using opioids or combination analgesics; highlighting that for more severe patients the treatment of $\mathrm{MOH}$ can be complex.

Strengths of this review include the use of rigorous systematic literature review methods to identify studies of real-world triptan use among patients with migraine and acute medication use among patients with $\mathrm{MOH}$; including those that focused on precisely estimating treatment patterns among incident triptan users as well as studies reporting on various outcomes among patients with $\mathrm{MOH}$. The following knowledge gaps in the literature were identified: (1) rates of WCS, with respect to the triptan dosage or route of administration, (2) headacherelated disability among patients who switch to a different triptan agents by the number of switches, and (3) the clinical, humanistic, and economic burden among triptan users that develop $\mathrm{MOH}$.

As with all evidence syntheses, this SLR was limited by the quality, validity, heterogeneity, and reporting accuracy of the included studies. Using the STROBE quality assessment tool we deemed the quality of the identified observational studies to be fair. Importantly, this quality assessment highlighted that only one study identified here described any efforts to address potential sources of bias. Variability in health care settings by country, study designs, data sources, patient populations, and how outcomes were defined across studies contributed to heterogeneity across estimates.

The variability in health care settings by country had many implications across the range of outcomes reported throughout this SLR. First, opioid use is more common in the US compared to in Europe as opioids are still widely used in the US to treat severe attacks in emergency departments $[9,10,49]$. Though this review only identified treatment patterns studies with relatively short follow-up it is important to understand the risk of opioid dependence among triptan non-responders, as other studies have suggested that opioid dependence among patients not adequately managed on triptans constitutes a significant public-health concern [56, 57]. Secondly, in certain countries triptans are available OTC (e.g. Japan and Germany) [40, 47]; therefore, not all triptan use would be captured in claims databases analysis, which contribute to underestimation of WCS rates. Furthermore, the timing of triptan uptake, overall and by agent and route of administration, varies by country and study period and thus was not consistent across the included studies. For example, in Imai et al. triptans were only overused by $2 \%$ of the sample; however, authors noted that triptans only recently entered the market in Japan at the time of study. Lastly, many patients manage their migraines with multiple acute medications at a time. Therefore, describing rates of acute medication use and success of withdrawal by medication agent is challenging. Two included studies described the differences in the clinical burden associated with $\mathrm{MOH}$ secondary to the use of triptans alone versus other treatments alone or in combination with triptans $[44,51]$. Creac'h et al. noted that compared to patients with $\mathrm{MOH}$ who were purely overusing triptans, patients overusing triptans in combination experience more frequent and severe migraine, and were characterized by stronger dependence on acute 


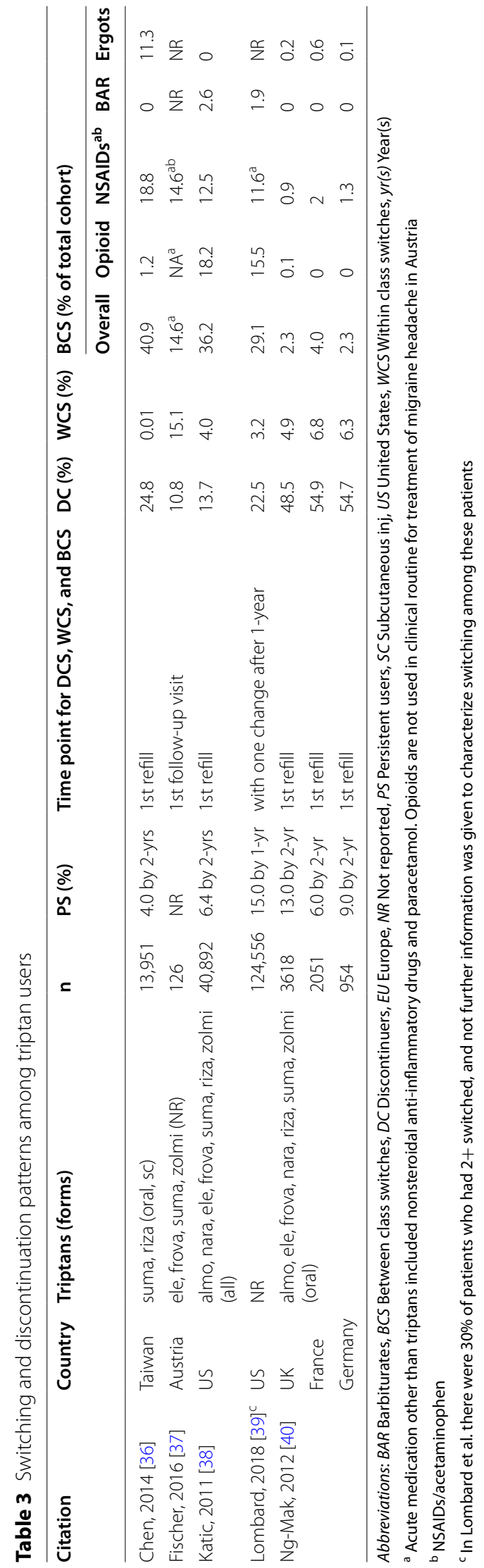




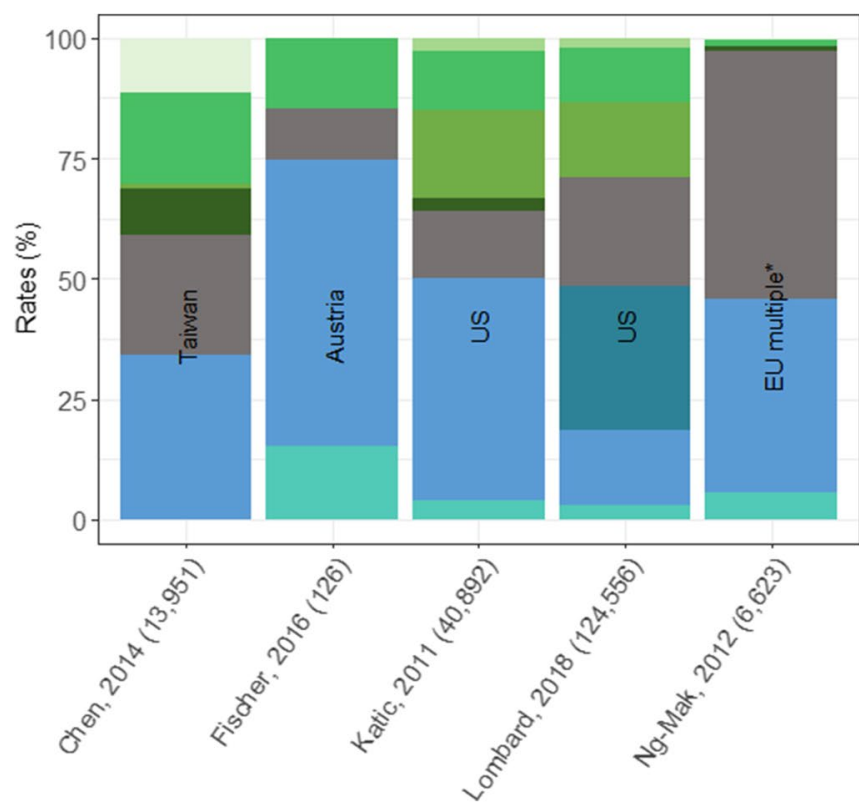

Outcome

BCS $(\%)$ - barbiturates

BCS (\%) - ergots

BCS (\%) - NSAIDs

BCS (\%) - opioids

BCS $(\%)$ - other

DC (\%)

other $(\%)+$

PS (\%)

WCS (\%)

Fig. 4 BCS, WCS and discontinuations by country and medication class. Abbreviations: $B C S=$ between class switches; $D C=$ discontinuers; $\mathrm{EU}=$ Europe; NSAID = nonsteroidal anti-inflammatory drug; PS = persistent users; WCS=Within class switches. Note: *Included UK, Germany, and France, +further details about switching patterns were only descried among patients with 1 switch during the follow-up period

Table 4 Medication overuse among triptan users with medication overuse headache

\begin{tabular}{|c|c|c|c|c|c|c|c|c|}
\hline \multirow[t]{2}{*}{ Citation } & \multirow[t]{2}{*}{$\mathrm{n}, \mathrm{MOH}$} & \multicolumn{7}{|c|}{ Medication overuse by class (\%) } \\
\hline & & Triptans & Analgesics & $\begin{array}{l}\text { Simple } \\
\text { analgesics }\end{array}$ & NSAIDS & $\begin{array}{l}\text { Combination } \\
\text { analgesics }\end{array}$ & Ergots & Opioids \\
\hline Benz et al., 2017 [42] & 51 & 14.0 & NR & $N R$ & NR & 24.0 & NR & 2.0 \\
\hline Chagas, 2015 [43] & 29 & 14.0 & NR & NR & 28.0 & NR & NR & NR \\
\hline Creac'h et al., 2009 [44] & 163 & 100 & NR & 42.0 & NR & 67.0 & 0.6 & 60.0 \\
\hline de Rijk et al., 2018 [45] & 79 & 31.7 & NR & 38.0 & 17.7 & 70.9 & 8.9 & 2.5 \\
\hline Grande et al., 2011 [46] & 109 & 6.0 & NR & 73.0 & NR & 19.0 & NR & NR \\
\hline Imai et al., 2007 [47] & 47 & 2.1 & 8.5 & NR & NR & 85.1 & 2.1 & 0.0 \\
\hline Katsarava et al., 2003 [48] & 96 & 39.0 & 48.0 & NR & NR & NR & 13.0 & NR \\
\hline Kluonaitis et al., 2017 [49] & 87 & 41.8 & NR & 38.8 & 27.3 & 38.8 & 1.5 & 16.1 \\
\hline Lake et al., 2009 [50] & 158 & 16.0 & NR & NR & NR & NR & $N R$ & 48.0 \\
\hline Limmroth et al., 2002 [51] & 96 & 39.0 & 48.0 & NR & NR & NR & 13.0 & 7.0 \\
\hline Radat et al., 2005 [52] & 41 & 46.3 & NR & $N R$ & 29.3 & NR & 22.0 & NR \\
\hline Zeeberg et al., 2006 [53] & 216 & 20.0 & NR & 29.0 & NR & 42.0 & 4.0 & 6.0 \\
\hline Zidverc-Trajkovic etr al, 2007 [54] & 240 & 18.9 & 70.8 & NR & 25.8 & 21.7 & 42.8 & 6.0 \\
\hline
\end{tabular}

Abbreviations: $M O H$ Medication overuse headache, NR Not reported, NSAID Nonsteroidal anti-inflammatory drug

a Same patient population, different outcomes

treatments of headaches [44]. Authors suggested that these patients may require a more intensive prophylactic therapy and specific behavioral management $[44,51]$.

Rates of switching and discontinuation among triptan users and rates of acute medication use among patients with $\mathrm{MOH}$ were characterized descriptively; because of the heterogeneity of patients across the included studies, no formal meta-analysis was performed. The mean age and the percentage of the sample who were female varied across the included studies. The headache classification used varied by study design (ICD in database studies vs. ICHD in cohort studies), by country, and over 
time. Specifically, the version of ICHD criteria for $\mathrm{MOH}$ used varied by study period; ICHD-II criteria was used in most studies. Furthermore, the headache frequency was infrequently reported, and the percentage of patients with previous migraine ranged from $8 \%$ [46] to $100 \%$ [43, $45,52]$, Together these strongly affected the difference in rates of acute medication use by agent among patients with $\mathrm{MOH}$. It is also important to note, that we required studies of confirmed MOH. Therefore, studies of patients with chronic migraine overusing acute medications were not described here, which may have led to identifying a more severe set of patients with $\mathrm{MOH}$ seen at inpatient and outpatient clinics. A future SLR describing rates of acute medication use among patients with choric migraine as well as patients with $\mathrm{MOH}$ is warranted.

\section{Conclusion}

Under current AHS guidelines, patients must either have contraindications to the use of triptans or have failed to respond to or tolerate at least two oral triptans to be considered for treatment with novel therapies [8, 23]. The evidence summarized here highlights that rates of WCS are low and many patients turn to other acute medication at their first refill. Patients may experience no improvement in disability when switching from one triptan agent to another, or experience increasing disability and/or increasing migraine frequency when turning to traditional acute treatment for migraine. Variability in health care settings, patient severity, and study design contributed to the heterogeneity across the identified studies.

\begin{abstract}
Abbreviations
SLR: Systematic literature review; NSAIDS: Nonsteroidal anti-inflammatory drug; CV: Cardiovascular; HRQoL: Health-related quality of life; WCS: Withinclass switching; $\mathrm{BCS}$ : Between-class switching; $\mathrm{MOH}$ : Medication overuse headache; AHS: America Headache Society; PICOS: Population, Intervention, Comparators, Outcomes Study Design; STROBE: Strengthening the reporting of observational studies; ICD-10: International Classification of Diseases, 10th addition; ICHD: The International Classification of Headache Disorders; NR: Not reported; OTC: Over the counter; AMPP: American Migraine Prevalence and Prevention; EU: Europe; IMS: Information Management System; MAST: Migraine in America Symptoms and Treatment; NHIR: National Health Insurance Research; SC: Subcutaneous inj; US: United States; U: University; MHD: Monthly headache days; Yr:Year; DC: Discontinuers; BAR: Barbiturates.
\end{abstract}

\section{Supplementary Information}

The online version contains supplementary material available at https://doi. org/10.1186/s12883-021-02451-x.

Additional file 1: Suppl Table 1. Search Strategy. Suppl Table 2. Systematic Review Selection Criteria. Suppl Table 3. STROBE statement recommendation checklist. Suppl Table 4. Quality assessment using STROBE.

\section{Acknowledgements}

Not applicable.

\section{Authors' contributions}

$A M D, K J$, and $L A H$ led the conduct of the SLR. AMD synthesized the data. AMD and KJ drafted the manuscript. All authors contributed to the design of the study and the content of the manuscript. All authors read and approved the final manuscript.

\section{Funding}

The design of this study, the conduct of the SLR, synthesis of the data, and drafting of this manuscript were sponsored by Biohaven Pharmaceuticals.

\section{Availability of data and materials}

All data presented in this systematic review are derived from published studies and are available from the first author on reasonable request.

\section{Declarations}

\section{Ethics approval and consent to participate}

Not applicable. For the systematic review we analyzed already published literature only.

\section{Consent for publication \\ Not applicable - Systematic literature review.}

\section{Competing interests}

$\mathrm{AMD}$ and $\mathrm{KJ}$ are employees of Broadstreet $\mathrm{HEOR}$, which received funds from Biohaven for this work. $L A H, S H, G L$, and VC are employees of Biohaven. LAQ was an employee of Biohaven at the time of study conduct.

\section{Author details}

'Broadstreet HEOR, 201-343 Railway St, Vancouver, BC V6A 1A4, Canada. ${ }^{2}$ Biohaven Pharmaceuticals, 215 Church Street, New Haven, CT, USA.

Received: 10 May 2021 Accepted: 6 October 2021

Published online: 02 November 2021

\section{References}

1. Steiner TJ, Stovner LJ, Vos T, Jensen R, Katsarava Z. Migraine is first cause of disability in under 50s: will health politicians now take notice? J Headache Pain. 2018;19(1):17.

2. Migraine Research Foundation. Migraine research. 2019.

3. Collaborators GBDH. Global, regional, and national burden of migraine and tension-type headache, 1990-2016: a systematic analysis for the global burden of disease study 2016. Lancet Neurol. 2018;17(11):954-76.

4. Stewart WF, Shechter A, Lipton R. Migraine heterogeneity. Disability, pain intensity, attack frequency and duration. Neurology. 1994;44(6 Suppl 4):S24-39.

5. Hu XH, Markson LE, Lipton RB, Stewart WF, Berger ML. Burden of migraine in the United States: disability and economic costs. Arch Intern Med. 1999;159(8):813-8.

6. Bonafede M, Cai Q, Cappell K, Kim G, Sapra SJ, Shah N, et al. Factors associated with direct health care costs among patients with migraine. J Manag Care Spec Pharm. 2017;23(11):1169-76.

7. Mayans L, Walling A. Acute migraine headache: treatment strategies. Am Fam Physician. 2018;97(4):243-51.

8. American Headache Society. The American headache society position statement on integrating new migraine treatments into clinical practice. Headache. 2019;59(1):1-18.

9. Peters GL. Migraine overview and summary of current and emerging treatment options. Am J Manag Care. 2019:25:S23-34.

10. Aukerman G, Knutson D, Miser WF. The management of the acute migraine headache. Am Fam Physician. 2002;66(11):2123.

11. Lipton RB, Marcus SC, Shewale AR, Dodick DW, Viswanathan HN, Doshi JA. Acute treatment patterns in patients with migraine newly initiating a triptan. Cephalalgia. 2020;40(5):437-47.

12. Lipton RB, Munjal S, Buse DC, Alam A, Fanning KM, Reed ML, et al. Unmet acute treatment needs from the 2017 migraine in America symptoms and treatment study. Headache. 2019;59(8):1310-23. 
13. Lombard L, Farrar M, Ye W, et al. A global real-world assessment of the impact on health-related quality of life and work productivity of migraine in patients with insufficient versus good response to triptan medication. J Headache Pain. 2020;21(1):41. Published 2020 Apr 29. https://doi.org/10. 1186/s10194-020-01110-9.

14. Lombard L, Farrar M, Ye W, Kim Y, Cotton S, Jackson J. A Real-world Assessment of the Impact on the Health-related Quality of Life and Work Productivity of Triptan Non-responders Compared with Responders: Results from a Global Study, 61st Annual Scientific Meeting American Headache Society ${ }^{\circledR}$ July 11 -14 2019 Pennsylvania Convention Center Philadelphia, PA. J Headache Pain. 2019;59:1-208. https://doi.org/10.1111/head.13549.

15. Schwedt TJ, Alam A, Reed ML, Fanning KM, Munjal S, Buse DC, et al. Factors associated with acute medication overuse in people with migraine: results from the 2017 migraine in America symptoms and treatment (MAST) study. J Headache Pain. 2018;19(1):38.

16. Schwedt TJ, Buse DC, Argoff C, Reed ML, Fanning KM, Manack Adams A, et al. Greater Headache-Related Burden and Disability Among Those with Medication Overuse: Results from the Chronic Migraine Epidemiology and Outcomes (CaMEO) Study. 61st Annual Scientific Meeting American Headache Society ${ }^{\circledR}$ July 11 -14 2019 Pennsylvania Convention Center Philadelphia, PA. J Headache Pain. 2019;59:1-208. https://doi.org/10. 1111/head.13549.

17. Diener H-C, Dodick D, Evers S, Holle D, Jensen RH, Lipton RB, et al. Pathophysiology, prevention, and treatment of medication overuse headache. Lancet Neurol. 2019;18(9):891-902.

18. Wilson M-C, Jimenez-Sanders R. Medication Overuse Headache. 2016. https://americanmigrainefoundation.org/resource-library/medicationoveruse/. Accessed 28 Oct 2021.

19. Saengjaroentham C, Strother LC, Dripps I, Sultan Jabir MR, Pradhan A, Goadsby PJ, et al. Differential medication overuse risk of novel antimigraine therapeutics. Brain. 2020;143(9):2681-8.

20. Thorlund K, Sun-Edelstein C, Druyts E, Kanters S, Ebrahim S, Bhambri R, et al. Risk of medication overuse headache across classes of treatments for acute migraine. J Headache Pain. 2016;17(1):107.

21. Carlsen LN, Munksgaard SB, Nielsen M, Engelstoft IMS, Westergaard ML, Bendtsen $\mathrm{L}$, et al. Comparison of 3 treatment strategies for medication overuse headache: a randomized clinical trial. JAMA Neurol. 2020;77(9):1069-78.

22. Dodick D, Freitag F. Evidence-based understanding of medication-overuse headache: clinical implications. Headache. 2006;46:S202-S11.

23. Lipton R, Pohl G, Araujo A, Nicholson R, Buse D, Shapiro R, et al. Who is eligible for novel medications designed for the acute treatment of migraine and what are their unmet needs? Results of the OVERCOME study. $61 \mathrm{st}$ Annual Scientific Meeting American Headache Society ${ }^{\circledR}$ July $11-14$ 2019 Pennsylvania Convention Center Philadelphia, PA. J Headache Pain. 2019;59:1-208. https://doi.org/10.1111/head.13549.

24. Tepper SJ, Silberstein SD, Rosen NL, et al. The Influence of Migraine on Driving: Current Understanding, Future Directions, and Potential Implications of Findings. Headache. 2020;60(1):178-89. https://doi.org/10.1111/ head.13716.

25. Silberstein S, Lipton R. Chronic daily headache, including transformed migraine, chronic tensiontype headache, and medication overuse. In: Silberstein S, Lipton R, Dalessio D, editors. Wolff's headache and other head pain. New York: Oxford University Press; 2001. p. 247-82.

26. U.S. Food and Drug Administration. REYVOW (lasmiditan) - FDA 2019. Available from: https://www.accessdata.fda.gov/drugsatfda_docs/label/ 2019/211280s000lbl.pdf. Accessed 1 Mar 2021.

27. U.S. Food and Drug Administration. UBRELVY (ubrogepant) - FDA 2020. Available from: https://www.accessdata.fda.gov/drugsatfda_docs/label/ 2019/211765s000lbl.pdf. Accessed 1 Mar 2021.

28. U.S. Food and Drug Administration. NURTEC ODT - FDA 2020. Available from: https://www.accessdata.fda.gov/drugsatfda_docs/label/2020/ 212728s000lbl.pdf. Accessed 1 Mar 2021

29. Messali AJ, Yang M, Gillard P, Tsai K, Tepper SJ, Bloudek LM, et al. Treatment persistence and switching in triptan users: a systematic literature review. Headache. 2014;54(7):1120-30.

30. Leroux E, Buchanan A, Lombard L, Loo LS, Bridge D, Rousseau B, et al. Evaluation of patients with insufficient efficacy and/or tolerability to triptans for the acute treatment of migraine: a systematic literature review. Adv Ther. 2020;37(12):4765-96. https://doi.org/10.1007/ s12325-020-01494-9.
31. Kristoffersen ES, Lundqvist C. Medication-overuse headache: epidemiology, diagnosis and treatment. Ther Adv Drug Saf. 2014;5(2):87-99.

32. Westergaard ML, Hansen EH, Glumer C, Olesen J, Jensen RH. Definitions of medication-overuse headache in population-based studies and their implications on prevalence estimates: a systematic review. Cephalalgia. 2014;34(6):409-25.

33. Moher D, Liberati A, Tetzlaff J, Altman DG, Group P. Preferred reporting items for systematic reviews and meta-analyses: the PRISMA statement. Int J Surg. 2010;8(5):336-41.

34. Elm EV, Altman DG, Egger M, Pocock SJ, Gøtzsche PC, Vandenbroucke $J P$, et al. The strengthening the reporting of observational studies in epidemiology (STROBE) statement: guidelines for reporting observational studies. Epidemiology. 2007;18(6):800-4.

35. Alam A, Munjal S, Reed M, Bostic R, Buse D, Schwedt T, et al. Triptan use and discontinuation in a representative sample of persons with migraine: results from migraine in America symptoms and treatment (MAST) study. Postgrad Med. 2018;130(Supplement 1):2-3.

36. Chen TB, Chen YT, Fuh JL, Tang CH, Wang SJ. Treatment adherence among new triptan users: a 2-year cohort study in Taiwan. J Headache Pain. 2014;15(1):48

37. Fischer M, Frank F, Wille G, Klien S, Lackner P, Broessner G. Triptans for acute migraine headache: current experience with triptan use and prescription habits in a tertiary care headache outpatient clinic: an observational study. Headache. 2016;56(6):952-60.

38. Katic BJ, Rajagopalan S, Ho TW, Chen YT, Hu XH. Triptan persistency among newly initiated users in a pharmacy claims database. Cephalalgia. 2011;31(4):488-500.

39. Lombard L, Schroeder K, Nichols R, Kar-Chan Choong C, Ye W. Characteristics, treatment patterns, and healthcare resource utilization in patients with migraine who initiated a triptan. Headache. 2018;58(Supplement 2):182-3.

40. Ng-Mak DS, Chen YT, Ho TW, Stanford B, Roset M. Results of a 2-year retrospective cohort study of newly prescribed triptan users in European nationwide practice databases. Cephalalgia. 2012;32(12):875-87.

41. Serrano D, Buse DC, Kori SH, Papapetropoulos S, Cunanan CM, Manack AN, et al. Effects of switching acute treatment on disability in migraine patients using triptans. Headache. 2013;53(9):1415-29.

42. Benz T, Nussle A, Lehmann S, Gantenbein AR, Sandor PS, Elfering A, et al, Health and quality of life in patients with medication overuse headache syndrome after standardized inpatient rehabilitation: a cross-sectional pilot study. Medicine (United States). 2017;96(47):e8493.

43. Chagas OFP, Eckeli FD, Bigal ME, Da Silva MOA, Speciali JG. Study of the use of analgesics by patients with headache at a specialized outpatient clinic (ACEF). Arq Neuropsiquiatr. 2015;73(7):586-92.

44. Creac'h C, Radat F, Mick G, Guegan-Massardier E, Giraud P, Guy N, et al. One or several types of triptan overuse headaches? Headache. 2009;49(4):519-28.

45. de Rijk P, Resseguier N, Donnet A. Headache characteristics and clinical features of elderly migraine patients. Headache. 2018;58(4):525-33.

46. Grande RB, Aaseth K, Benth JS, Lundqvist C, Russell MB. Reduction in medication-overuse headache after short information. The Akershus study of chronic headache. Eur J Neurol. 2011;18(1):129-37.

47. Imai N, Kitamura E, Konishi T, Suzuki Y, Serizawa M, Okabe T. Clinical features of probable medication-overuse headache: a retrospective study in Japan. Cephalalgia. 2007;27(9):1020-3.

48. Katsarava Z, Limmroth V, Finke M, Diener HC, Fritsche G. Rates and predictors for relapse in medication overuse headache: a 1-year prospective study. Neurology. 2003;60(10):1682-3.

49. Kluonaitis K, Petrauskiene E, Ryliskiene K. Clinical characteristics and overuse patterns of medication overuse headache: retrospective case-series study. Clin Neurol Neurosurg. 2017;163:124-7.

50. Lake IAE, Saper JR, Hamel RL. Comprehensive inpatient treatment of refractory chronic daily headache. Headache. 2009;49(4):555-62.

51. Limmroth V, Katsarava Z, Fritsche G, Przywara S, Diener HC. Features of medication overuse headache following overuse of different acute headache drugs. Neurology. 2002;59(7):1011-4.

52. Radat F, Creac'h C, Swendsen JD, Lafittau M, Irachabal S, Dousset $V$, et al Psychiatric comorbidity in the evolution from migraine to medication overuse headache. Cephalalgia. 2005;25(7):519-22.

53. Zeeberg P, Olesen J, Jensen R. Probable medication-overuse headache: the effect of a 2-month drug-free period. Neurology. 2006;66(12):1894-8. 
54. Zidverc-Trajkovic J, Pekmezovic T, Jovanovic Z, Pavlovic A, Mijajlovic M, Radojicic A, et al. Medication overuse headache: clinical features predicting treatment outcome at 1-year follow-up. Cephalalgia. 2007;27(11):1219-25.

55. Rossi P, Faroni JV, Nappi G. Medication overuse headache: predictors and rates of relapse in migraine patients with low medical needs. A 1-year prospective study. Cephalalgia. 2008;28(11):1196-200.

56. Harris L, Mohajer A, Dandona H, et al. Migraine Patients Exhibit Increased Risk Of Opioid Dependence With Sustained Triptan Treatment - Results
From A Large-Scale Real-World Claims Analysis (2403). Neurology. 2021;96(15 Supplement):2403.

57. Buse DC, Pearlman SH, Reed ML, Serrano D, Ng-Mak DS, Lipton RB. Opioid use and dependence among persons with migraine: results of the AMPP study. Headache. 2012;52(1):18-36.

\section{Publisher's Note}

Springer Nature remains neutral with regard to jurisdictional claims in published maps and institutional affiliations.
Ready to submit your research? Choose BMC and benefit from:

- fast, convenient online submission

- thorough peer review by experienced researchers in your field

- rapid publication on acceptance

- support for research data, including large and complex data types

- gold Open Access which fosters wider collaboration and increased citations

- maximum visibility for your research: over $100 \mathrm{M}$ website views per year

At BMC, research is always in progress.

Learn more biomedcentral.com/submissions 